\title{
Prosocial Behaviors: The Influence of Authoritarian Parenting Style on Adolescents' Prosocial Behaviors Towards Friends and Strangers
}

\author{
Krista-Gay Shaniece Chantal Taylor \\ West Virginia University, kstaylor@mix.wvu.edu
}

Follow this and additional works at: https://researchrepository.wvu.edu/etd

Part of the Education Commons, and the Social and Behavioral Sciences Commons

\section{Recommended Citation}

Taylor, Krista-Gay Shaniece Chantal, "Prosocial Behaviors: The Influence of Authoritarian Parenting Style on Adolescents' Prosocial Behaviors Towards Friends and Strangers" (2020). Graduate Theses, Dissertations, and Problem Reports. 7795.

https://researchrepository.wvu.edu/etd/7795

This Thesis is protected by copyright and/or related rights. It has been brought to you by the The Research Repository @ WVU with permission from the rights-holder(s). You are free to use this Thesis in any way that is permitted by the copyright and related rights legislation that applies to your use. For other uses you must obtain permission from the rights-holder(s) directly, unless additional rights are indicated by a Creative Commons license in the record and/ or on the work itself. This Thesis has been accepted for inclusion in WVU Graduate Theses, Dissertations, and Problem Reports collection by an authorized administrator of The Research Repository @ WVU. For more information, please contact researchrepository@mail.wvu.edu. 
Prosocial Behaviors: The Influence of Authoritarian Parenting Style on Adolescents' Prosocial Behaviors Towards Friends and Strangers

Krista-Gay Shaniece Chantal Taylor

Follow this and additional works at: https://researchrepository.wvu.edu/etd

Part of the Education Commons, and the Social and Behavioral Sciences Commons 
Prosocial Behaviors: The Influence of Authoritarian Parenting Style on Adolescents' Prosocial Behaviors Towards Friends and Strangers

\author{
Krista-Gay Taylor \\ Thesis submitted to the \\ College of Human Resources and Education \\ at West Virginia University \\ in partial fulfillment of the requirements for the degree of \\ Master of Arts \\ In Educational Psychology \\ With an emphasis in Child Development and Family Studies \\ Kristin L. Moilanen, Ph.D. \\ Amy E. Root, Ph.D. \\ Amy Gentzler, Ph.D. \\ Department of Learning Sciences \& Human Development
}

Morgantown, West Virginia

2020

Keywords: prosocial behaviors, parenting styles, physical coercion, verbal hostility, nonreasoning/punitive, adolescents, friends, strangers

Copyright 2020 Krista-Gay Taylor 


\begin{abstract}
Prosocial Behaviors: The Influence of Authoritarian Parenting Style on Adolescents' Prosocial

Behaviors Towards Friends and Strangers
\end{abstract}

\begin{abstract}
Krista-Gay Taylor
Adolescence is the period of development of many negative and positive behaviors. On the positive side, prosocial behaviors are positive behaviors that become more prominent in adolescents. Many of the studies that explore prosocial behaviors have explored it during childhood rather than in adolescence. Additionally, few have assessed specific parenting styles, like authoritarian parenting and its influence on adolescents' prosocial behaviors within distinct relationships. Therefore, the aims of this study were to assess how the maternal authoritarian parenting style is associated with adolescents' prosocial behaviors. I also explored how the association between these two variables differ for friends and strangers (i.e., it was expected to be stronger for friends than strangers). Participants were $N=463$ adolescents between the ages of 13 and 18 years old (51.9\% female, 64\% European American) and their mothers from Wave V of the Flourishing Families Project. Correlations revealed that authoritarian mothers had adolescents who reported lower prosocial behaviors with friends. Still, regressions controlling for demographic variables showed no associations between authoritarian parenting and prosocial behaviors with friends or strangers. Implications include assisting parents of adolescents in promoting prosocial behaviors. Implications of this study lie within assessing ethnicity as a moderator rather than a control variable to capture the overall rationale behind these compelling findings.
\end{abstract}




\section{Acknowledgments}

This Master's thesis is dedicated to my mother, family, and graduate school classmates. You have pushed me through the most stressful and most challenging times, and I love and appreciate all the support that you have given me. To my mother, although you are out of your struggles and in a better place, I will never forget how confident you were in me and how you did your best to encourage me even when I felt as if success was impossible. To my family, I appreciate the love and support you showed me even while far away. To my graduate classmates, you understood the pressures of a thesis and assisted me in every step of the way when possible and made this journey worthwhile. 
References 


\section{PROSOCIAL BEHAVIORS}

\section{Chapter I}

\section{Introduction}

While individuals engage in a variety of behaviors in their lifetime, prosocial behaviors have been found to have strong impacts on various aspects of adolescents (Van der Graaff, Carlo, Crocetti, Koot, \& Branje, 2018). This study will examine adolescents' prosocial behaviors, which has been defined by researchers as positive social behaviors with the genuine intent to help others (Gryczkowski, Jordan, \& Mercer, 2018; Padilla-Walker, Carlo, Christensen, \& Yorgason, 2012). Examples include helping, sharing, emotional support, showing empathy, donating, and volunteering (Chen et al., 2018; Wentzel, Fillisetti \& Barry, 2018).

Prosocial behaviors are a predictor of positive development in childhood and adolescence. Many studies suggest that prosocial behavior is an indicator of adolescents' ability to engage in positive social, emotional, and cognitive skills and behaviors with others (Van der Graaff et al., 2018). At an internal level, prosocial behavior aids with the development of a sense of meaning through the motivation of wanting to do good for others (Yang, $\mathrm{Li}, \mathrm{Fu}, \& \mathrm{Kou}$, 2017). Interpersonally, adolescents who engage in high levels of prosocial behaviors tend to possess a more profound understanding of others' emotions, which in turn influences their ability to engage in perspective-taking (Padilla-Walker, Memmott-Elison, \& Coyne, 2018; Shaffer, 2009; Van der Graaff et al., 2018). Consequently, evidence has shown that highly prosocial youth have overall positive social development. Chen et al. (2018) also indicated that prosocial behaviors are positively linked to school adjustment; specifically, more prosocial children tended to engage in more positive social interactions with peers and exhibited fewer problem behaviors. Along these lines, prosocial behavior has also been linked to children's self-esteem, psychological development, and sympathy for others (Padilla-Walker et al., 2018). In short, these 


\section{PROSOCIAL BEHAVIORS}

children are more likely to possess higher self-confidence and a better understanding of others' needs and feelings. Prosocial behavior is associated with higher academic achievement (Ishak, Low, \& Lau, 2012) and avoiding behavioral problems and maladjustment (Padilla-Walker, Carlo, \& Nielson, 2015). Thus, it is vital to understand the development of prosocial behaviors because of their wide-reaching impacts.

During adolescence, prosocial behaviors become more evident and frequent than in childhood, but different scholars offer distinct explanations of the source of developments in prosocial behaviors. It is necessary to study this in adolescence as there physical maturity increases during this period, which in turn increases additional dimensions that improve social development and competency (Padilla-Walker et al., 2018; Van der Graaff et al., 2018). During this period, there is a more significant increase in perspective-taking abilities that are related to engaging in prosocial behaviors. Furthermore, engaging in prosocial behavior requires the support of advanced social-cognition skills to improve social well-being (Padilla-Walker et al., 2015). During the adolescent period, physical and brain maturity and autonomy take place, which influences this developmental increase (Van der Graaff et al., 2018). As a result, perspective-taking is more pronounced, which in turn shapes empathic concerns as individuals understand how others feel in a stressful situation. Subsequently, this influences the development of prosocial behavior, that is, helping others (Van der Graaff et al., 2018).

As discussed at length below, another approach focuses on relationships. The acquisition and development of prosocial behaviors occur within interactions with parents, family members, peers, friends, and strangers (Hastings, Miller, \& Troxel, 2016). For children and adolescents to gain the necessary prosocial skills that are needed to engage in positive behaviors and interactions with others, they learn these skills when they socialize with the people around them. 


\section{PROSOCIAL BEHAVIORS}

Parents and peers are the primary socializing agents of prosocial behaviors (Belgrave, Nguyen, Johnson, \& Hood, 2011; Hastings et al., 2016; Wentzel et al., 2018). Much research from this tradition has explored parenting styles as a predictor of adolescents' prosocial behavior (Carlo, McGinley, Haye, Batenhorst, \& Wilkinson, 2007). Parenting styles are attitudes and strategies used by parents to shape children's behaviors and attitudes (Baumrind, 1966). These styles possess similarities and differences in the expectations of children's actions as well as the attitudes and behaviors engaged in transmitting these expectations (Baumrind, 1966; Baumrind, 1973). The focus of the current study is the maternal authoritarian parenting style and how this influences adolescents' prosocial behavior towards friends and strangers.

\section{Justification of the Study}

While all these gaps are crucial in understanding parenting and its characteristics that shape prosocial behaviors, it is more important first to assess parenting styles versus the practices associated with authoritarian parenting. This will later give insights into extensive studies with younger children, necessary to understand why possible results that exist among adolescents. First, research studies have mostly assessed authoritarian practices rather than the overarching parenting style in considering their impact on adolescents' prosocial behaviors (Gryczkowski et al., 2018). Therefore, there is a gap in the literature, in that it remains unclear whether the combination of practices matters for prosocial behaviors. Second, previous studies have explored the positive or negative influences of parenting styles on prosocial behaviors, but mainly with younger children. Thus, we need to examine adolescents to understand whether parenting has similar impacts as in childhood. Third, much of the research has been on the general influence of authoritarian parenting on prosocial behaviors with unspecified beneficiaries and little related to the specific relationships with friends and others/strangers. Therefore, prosocial behaviors may 


\section{PROSOCIAL BEHAVIORS}

differ across these two relationships because of distinct motives (an issue discussed further below). Hence, it is crucial to research authoritarian parenting styles concerning their influences on adolescents' prosocial behaviors with two specific groups, friends, and strangers, as compelling findings may emerge.

\section{Statement of the Problem}

There has been considerable scholarly attention to the associations between parenting and prosocial behaviors in childhood, but less in adolescence. Therefore, the first aim of this study is to examine the role of maternal authoritarian parenting and how this is associated with adolescents' prosocial behaviors. Little research has explored and found that when the authoritarian parenting style is present, this will negatively impact adolescents' prosocial behaviors in general (Van der Graaff et al., 2018). However, questions remain about whether parenting has similar impacts on prosocial behaviors in distinct relationships. Thus, the second aim of this study is to explore how this parenting is a positive influencer or inhibitor of prosocial behaviors towards friends and strangers. 
PROSOCIAL BEHAVIORS

\section{Chapter II}

\section{Literature Review}

A large proportion of studies have assessed the relationship between parenting and prosocial behaviors. To understand the role that parents (particularly mothers) play in influencing adolescents' prosocial behavior, it is vital to explore what parenting styles contribute to these behaviors. Parenting styles consisting of positive, demanding, and supportive patterns, which is associated with authoritative parenting, are particularly likely to be positively related to adolescents' prosocial behavior (Hastings et al., 2015). At the same time, little research has examined the relationships between authoritarian parenting and prosocial behavior in adolescents (Williams et al., 2009). Little concrete evidence has been found when authoritarian parenting or associated practices have been considered. It is essential to explore this path because parenting styles, as well as practices, have been found to identify differing trends in children's prosocial behaviors when assessed separately (Gryczkowski et al., 2018).

\section{Theoretical Framework}

Results from various studies have shown that there are multiple sources of prosocial behaviors. Two approaches that have been used to explain these sources are the dispositional and relational approach. The present study aligns with the relational perspective, which I describe below after a brief overview of the dispositional framework.

Dispositional approach. The dispositional approach to prosocial behavior takes the stance that a persons' disposition/inherent characteristics influence prosocial behaviors, including temperamental traits and other internal characteristics such as sympathy (PadillaWalker, Nielson, \& Day, 2016). Specifically, traits related to acting prosocially, such as being sympathetic, and being able to self-regulate, develop with time (Moilanen, Rasmussen, \& 


\section{PROSOCIAL BEHAVIORS}

Padilla-Walker, 2014). Also, researchers have explained that the genetic aspect of an individual, such as variation in temperament (for example, regulation), influences how prosocial behaviors differ from one person to another (Eisenberg et al., 2002). According to another theoretical framework that aligns with the dispositional approach, the goal theory of happiness, individuals engage in a pattern of behaviors to achieve their desired goals or orientations of happiness (Yang et al., 2017). How people seek their desired ways to be happy and to improve their subjective well-being may be directly or indirectly through prosocial behaviors via relations with others.

Relational approach. In addition to the dispositional angle, prosocial behaviors are also evident through the relational approach. The relational approach to prosocial behavior explains that engaging in prosocial behavior is influenced by the type of relationship that the individual has with the people they are prosocial towards, such as close kin and those with whom they share common interests (Padilla-Walker et al., 2016). For example, when parents are supportive and engage in warm and reciprocal interactions with their children, it provides a space for children to easily communicate, build ties, acquire and reproduce expected behaviors and values of parents (Hastings et al., 2015). This approach aligns with the social learning theory and Baumrind's theory of parenting styles. Particularly, children learn behaviors from their parents, which guide how they act with their parents and as well as those outside their immediate family, such as friends and strangers. Although this is evident, still, others take a combination approach. Others have explained that it is the relationship between disposition and the relational facets that gives rise to the development of prosocial behaviors (Spinrad \& Knafo-Noam, 2015). In particular, when individuals bring their unique dispositional qualities alongside the relational influences such as the relationships that individuals have, these collectively shape the way each person is prosocial in one way or another. For example, children with a difficult temperament 


\section{PROSOCIAL BEHAVIORS}

characterized by high negative emotionality, they are more likely to engage in prosocial interactions with others when their parents and are warm and sensitive in their parenting styles (associated with authoritative parenting style). On the other hand, when a child possesses this same trait and has parents who are harsh and negative in their parenting style (associated with authoritarian parenting style), the child tends to have more externalizing behaviors such as aggression. This negatively impacts engagement in prosocial behaviors as their interactions with others would compose of aggression or negative emotionality (Bates \& Pettit, 2015).

As already discussed, parents, through socialization strategies, are responsible for their children's social competence and behaviors with others (Padilla-Walker et al., 2016). Attachment may also be taken into consideration when assessing the developmental process to arrive at why and how children are prosocial with others. In particular, attachment theory explains that parents utilize different parenting behaviors such as warmth and responsiveness and are responsible for secure attachment between them and their children (Anderson \& Beauchamp, 2012). This, in turn, positively influences/associated with children's engagement in prosocial interactions that mirror this, such as sharing and cooperating. It is the parents' sensitivity and reinforcement of expected behaviors that influence the child's understanding intent and reasons for their behaviors, that is, their internal working model, that motivates their engagement in prosocial behaviors (Anderson \& Beauchamp, 2012; Hastings et al., 2015).

Reflecting on the present study's consideration of variations in prosocial behavior across social relationship types, this study aligns with the relational approach to understanding prosocial behavior. The present study focuses on maternal parenting and is aligned with Baumrind's Theory of Parenting Styles and is informed by Bandura's Social Learning Theory (SLT). Each theory is explained in turn below. 


\section{PROSOCIAL BEHAVIORS}

Social learning theory. In general, the social learning theory supports the idea that children learn and adapt behaviors through observation and modeling from the people around them, especially parents (Kuppens, Laurent, Heyvaert, \& Onghena, 2013; Maccoby, 2015). Children experience and acquire a range of actions and behaviors necessary for social functioning through interactions with their social environments (Caprara, Kanacri, Zuffiano, Gerbino, \& Pastorelli, 2015; Kuppens et al., 2013; Shin, 2017). With this theory, adolescents are also continually acquiring and developing a greater understanding of other's feelings through direct experiences such as observations and modeling. They remember these behaviors and reproduce theme when interacting with others. For example, children may learn how to be sympathetic from observing and modeling this behavior from those in their environment, which positively influences their prosocial behaviors, that is, this encourages them to treat others similar to how they have been treated in regards to prosociality (Caprara et al., 2015).

Parenting styles. The parent-child relationship is a significant context in which such social learning occurs (Hay, 1979). Parents use different practices and styles to shape their adolescents' behaviors and attitudes, which they acquire and exhibit through their actions with others. The most prevailing theory drawn on when exploring parenting styles is Baumrind's Theory of Parenting Styles. Baumrind (1966) stated that a family might take any of the following parenting styles: authoritative, authoritarian, and permissive-indulgent styles. The authoritative parenting style includes high warmth, responsiveness, support, involvement, and control. This includes parents' communication of clearly defined expectations of behaviors, being responsive to the child's needs, and allowing and encouraging the child to partake in decision-making processes. Authoritarian parenting is high in demandingness and low in support and responsiveness. This involves parents clearly defined expected behaviors with an explanation of 


\section{PROSOCIAL BEHAVIORS}

consequences if these behaviors are unmet (Hastings et al., 2015). They are inflexible, in that children do not part take in decision making of consequences as the parents believe they have all power over their child's behaviors and relationships. On the other hand, permissive-indulgent parenting is characterized by high responsiveness and low in demandingness. This style includes parents having leniency when dealing with their child's negative behaviors, and there is little to no consistency in boundaries in the discipline (Williams et al., 2009). However, parents who adopt this style are caring, nurturing, and affectionate to their children's needs. This theory posits that children acquire a range of behaviors based on the different parenting styles that parents exhibit, in addition to their parents' expectations of them. Specific associations between parenting styles, their associated practices, and prosocial behaviors are discussed in detail further below. Briefly, many studies have found that authoritative parenting, which is characterized by high parental responsiveness and demandingness, is a predictor of high levels of prosocial behavior (Padilla-Walker et al., 2012). Particularly, when parents are high in demandingness or support but also provide reasons behind their demands, children tend to be more open and feel more comfortable in exploring relationships with others, especially those that show similar attributes to their parents' authoritative style. This encourages them to engage in similar behaviors of positivity, such as helping and sharing, which are some prosocial behaviors (Padilla-Walker et al., 2012). Additionally, a study by Padilla-Walker et al. (2012) utilized data from a longitudinal study to assess authoritative parenting and adolescents' observed and selfreported prosocial behaviors through a bidirectional lens, explained that Baumrind also supported this phenomenon, where the authoritative parenting style is positively associated with prosocial behavior, that is, authoritative parenting that involves demandingness through rules about preferred behaviors and why these behaviors matter, fosters adolescents' prosocial 


\section{PROSOCIAL BEHAVIORS}

behavior. However, this is different for views on authoritarian parenting. According to Hastings et al. (2016), the authoritarian parenting style inhibits the development of prosocial behavior. Authoritarian parenting hinders adolescents' prosocial behavior due to low support but high demanding behaviors that these parents use (Mesurado \& Richaud, 2017; Sim \& Chin, 2014). This occurs due to the presence of hostility and accompanied negative parenting behaviors such as being unempathetic, which impedes prosocial development as individuals tend to model these harsh and negative behaviors that are unsuitable for and hinders relations that support

prosociality (Hastings et al., 2016). For example, parents who engage in harsh parenting tend to have children who have low emotional regulation (Kawabata, Alink, Tseng, van IJzendoorn, \& Crick, 2011). Therefore, when faced with situations with peers that cause them to disagree, they may get upset and may engage in physical or relational aggression with them (Wang, 2019). A similar study by Jabeen et al. (2013), who cross-sectionally assessed how parenting styles predicted emotion regulation among adolescents, found when children acquire negative emotions such as aggression through the influence of negative parenting composed of harshness and control, this negatively affects their behaviors with others including the inability to regulate emotions. This, in turn, negatively affects social interactions as self-regulation abilities are necessary for engaging in prosocial behaviors (Moilanen et al., 2014).

Although these theories explore and explain parenting styles and prosocial behaviors in a more simplistic light, other areas of research reveal more complicated dynamics. One such study that radiates this is Carlo et al. (2007) and their cross-sectional study on parenting styles and practices in understanding sympathy and prosocial behaviors in adolescents through self-reports. The researchers sought to examine how identified aspects of parenting styles and practices were related to sympathy and prosocial behaviors among adolescents. It was hypothesized that when 


\section{PROSOCIAL BEHAVIORS}

parents engage in child-centered communication practices that are related to internalizing norms, this will be a predictor of children's prosocial behaviors. It was also hypothesized that high responsiveness and demandingness would be an indicator of high prosocial behaviors. This prediction was not supported in the bivariate correlations, in that high responsiveness was associated with only high compliant prosocial behavior, and demandingness was not correlated with any dimension of prosocial behavior. Instead, the other parenting practices specific to the socialization of prosocial behaviors significantly predicted adolescents' prosocial behaviors, and some of these relationships were mediated by sympathy was concerned. In particular, parents who engage in parenting practices characterized by conversations about prosocial behaviors such as sharing and helping. The results of this are understood to be mediated by sympathy, that is, children's understanding of others' feelings and emotions. Therefore, they engage in prosocial behaviors that they acquire from conversations with their parents that will make others feel good. Findings from this study provide insight into the importance of the complicating nature of research in parenting styles when assessing prosocial behaviors in adolescents, and that one theory or exploration of research will not always suffice how these relationships work.

\section{Literature on Parenting and Prosocial Behavior}

To date, few studies have assessed parenting styles, with the majority of that work focused on the authoritative parenting style. Much more common are considerations of how different levels of authoritarian-type parenting practices are associated with prosocial behavior. Parenting practices are childrearing behaviors, such as parental discipline (McKinney et al., 2011), control (McKinney et al., 2011; Yoo, Feng, \& Day, 2013), and warmth/responsivity (Padilla-Walker et al., 2016). In general, parenting styles and practices have each been studied somewhat interchangeably in the literature on prosocial behaviors (Eisenberg et al., 2015). High 


\section{PROSOCIAL BEHAVIORS}

levels of these practices, specifically parental discipline and control, align with the authoritarian parenting style, which impacts adolescents' prosocial behavior (Kokkinos \& Voulgaridou, 2016). Due to this overlap, as well as evidence that parenting behaviors are more effective in some situations than are parenting styles (Carlo et al., 2007), this literature review will discuss both the authoritarian parenting style and its associated parenting practices (i.e., dimensions of physical coercion/discipline, verbal hostility, non-reasoning/punitive discipline). Due to the problematic nature of separating parenting styles from parenting practices, both need to be discussed to gain a better understanding of how they influence adolescents' prosocial behavior. Below, I discuss the literature on the authoritarian style before the literature on the discrete practices associated with that style.

Authoritarian style and prosocial behavior. Much research has found various relationships between different parenting styles and adolescents' adjustment outcomes in general. Even though many studies have explored the authoritative parenting style due to it being found to be the most effective in eliciting more positive outcomes such as prosocial behavior (Carlo et al., 2007), there has been little research on the authoritarian parenting style and prosocial behavior in particular. The reason for this gap is unclear. Although there is a lack of research surrounding the influence of authoritarian parenting directly on prosocial behaviors, there are studies that have produced results that indicated that authoritarian parenting is unfavorable for the other aspects of adjustment that are related to prosocial behaviors. This includes self-esteem and anxiety (McKinney, Milone, \& Renk, 2011), and aggression (Kawabata et al., 2011). A longitudinal study by Steinberg et al. (1994) which assessed changes overtime when examining the relationships between parenting styles, and adjustment and competence, found that kids who had authoritarian parents were disadvantaged in terms of distress and 


\section{PROSOCIAL BEHAVIORS}

competence. Each of these is, in turn, were associated with prosocial behavior (Padilla-Walker et al., 2015). In this study by Steinberg et al. (1994), the researchers utilized data from a one-year follow up with adolescents to assess social and emotional competence and adjustment. The researchers reported that adjustments among adolescents varied based on the mothers' and fathers' parenting style (authoritative, authoritarian, or neglectful) they received. For example, they reported that parents who were overly controlling and overpowering, which are characteristics associated with an authoritarian parenting style, had adolescents who had more significant issues regarding competency and were high on psychological and somatic distress. On the other hand, parents who were authoritative in their parenting style had adolescents who had fewer issues in competency, where they showered higher levels of academic self-concept.

Alongside this, authoritative parenting has been a more favorable style for positively predicting adolescents' prosocial behaviors in different waves of the same dataset employed for the present investigation. For example, in a longitudinal study by Padilla-Walker et al. (2012), the researchers sought to investigate how the authoritative parenting style was related to prosocial behaviors in adolescents towards family members using a bidirectional approach. Participants of this study included children between ages 11 and 15 years and their parents from the Flourishing Families Project (i.e., different waves of the same dataset used for this study). Parents and their adolescents completed measures of authoritative parenting and prosocial behaviors towards family members. Information on authoritative parenting styles characterized by connection, regulation, and autonomy granting, and prosocial behaviors characterized by were measured using reports and observations. They assessed how parents engaged in these behaviors by asking adolescents and parents questions that fit the subscales listed above (sample item: "My parent is/I am responsive to my/my child's feelings and needs"). For measuring prosocial 


\section{PROSOCIAL BEHAVIORS}

behaviors, the researchers used a measure used to assess prosocial behavior with strangers and tailored it for their study to assess prosocial behaviors with family members. Adolescents' prosocial behaviors were measured using the dimensions of helpfulness, sensitivity, cooperation, sympathy, and respectfulness. It was reported that prosocial behaviors positively influenced authoritative parenting. This is evident as parenting is a fluid process, and when adolescents are prosocial to their parents, this shape and configure authoritative parenting. Also, adolescents' prosocial behaviors showed a substantial impact on mothers' authoritative parenting. More specifically, the researchers explained reported that adolescents' showing prosocial behaviors might be a result of the positive aspects of parenting, which includes these mothers modeling and engaging in moral conversations that fosters prosocial behaviors. Results also showed that prosocial behaviors were more stable for the reports but not the observation of prosocial behaviors. Stability was also evidence concerning individual differences. The researchers explained that this finding might be a result of genetic and environmental consistency. This is consistent with results of a separate study by Padilla-Walker et al. (2016) which found that parents who engage in authoritative parenting, in particular, encouraging social rewards and conversations about demands, have adolescents who engage in prosocial behaviors and that these effects are stable from childhood to adolescence.

Importantly, parenting is a complicated concept and not limited to parenting styles. Whereas some studies explore parenting styles, others investigate specific behaviors utilized by parents to guide their children's behaviors, parenting practices.

\section{Parenting practices that characterize the authoritarian parenting style. Alongside} parenting styles, many studies have focused on the role of parenting practices, which are considered to influence parenting styles (McKinney et al., 2011). Additionally, parenting styles 


\section{PROSOCIAL BEHAVIORS}

and practices have been studied individually in separate studies, as well as explored simultaneously, that is, within the same study to assess whether one, the other, or both are responsible for developmental outcomes (Hastings et al., 2015). Based on this, three categories of practices associated with authoritarian parenting styles that align with the dataset of this study will be considered: verbal hostility, physical coercion, and nonreasoning/punitive strategies.

Verbal hostility. Parents significantly influence prosocial behavior in adolescents. Parental warmth and hostility are two aspects of parenting that does this (Padilla-Walker et al., 2016). These are important to consider, as they both, in their unique ways, can make or break prosocial behavior. Studies have shown that parental warmth is a predictor of prosocial behavior. In contrast, parental hostility has been shown to heighten negative behaviors in adolescents, such as aggression, which is negatively associated with prosocial behavior. To communicate demands and discipline to their children, parents may engage in verbal hostility. When a child disobeys or does not engage in desired behaviors of the parent, they may engage in a variety of behaviors that characterizes verbal hostility. These strategies include yelling and shouting, exploding in anger, and frustration (Padilla-Walker et al., 2016). Based on another study, a cross-sectional one conducted by McKinney et al. (2011), mothers' and fathers' verbal hostility was evident in their subscale of psychological aggression of conflict tactics, that children perceived that their parents engaged in to discipline them. This was characterized by hitting, shaking, yelling, and screaming at their adult child, whose age is between 18 and 22 years. Although the researchers did not give detailed information on verbal hostility, they reported that the authoritarian parenting style was associated with emotional adjustment. In particular, for adult children who reported experiencing perceived authoritarian parenting style characterized by this kind of verbal hostility, they found high issues in emotional adjustment including high anxiety, low self-esteem, and high depression 


\section{PROSOCIAL BEHAVIORS}

within father to daughter and mother to daughter interactions. As Van der Graaff et al. (2018) explained, aspects of emotional adjustments are necessary for prosocial behaviors in that, for example, cognitive empathy and empathic concerns help children understand others' emotions and engage in prosocial behaviors so that others will feel good. However, anxiety, low selfesteem, and depression do not allow for this as it may block awareness of their own and others' emotions (Schacter \& Margolin, 2018).

Another study, Padilla-Walker et al. (2016) examined in their longitudinal study, parental (mother and father) hostility in relation to adolescents' prosocial behavior, specifically how parental hostility along with parental warmth influences prosocial behaviors with multiple targets. Firstly, it was hypothesized that parenting would be significantly associated with multiple targets, specifically with family, friends, and strangers. Aligned with previous studies, it was hypothesized that parental warmth would be associated with adolescents' prosocial behavior, while parental hostility would be negatively associated. To assess this, the researchers conducted a longitudinal study of 500 adolescents. Three periods were considered and they were one year apart. Parenting, specifically, parental warmth (e.g., being responsive) and hostility (e.g., yelling and shouting), were measured using parent reports of their parenting and adolescents' reports of their parents' parenting. Prosocial behavior was measured using selfreports and observation of specific prosocial behaviors. Information from the observations was coded into prosocial behavior towards mother and prosocial behavior towards father. In the results, parental warmth provided distinctive results for mothers and fathers. When mothers were warm, adolescents engaged in prosocial behaviors with family members and mothers, but when fathers were warm, adolescents were more likely to prosocial with friends and their fathers. Though this was present, parental warmth than parental hostility was less likely to influence 


\section{PROSOCIAL BEHAVIORS}

prosocial behavior across time positively. Fathers with hostile parenting had adolescents who did not engage in prosocial behavior with multiple targets, but this was different for mothers. For highly hostile parents, their adolescents showed low levels of prosocial behaviors with family, friends, or strangers. Still, no relationship was evident between hostile mothers and adolescents' engagement in prosocial behaviors. These results indicate that parents' warmth and hostility influences adolescents' prosocial behavior over time, as well as the different targets they engage in prosocial behaviors.

Physical coercion. Physical coercion, the construct utilized for this study, is a parenting practice characterized by physical discipline, which involves hitting and spanking to convey some level of authority over adolescents (Laible, Thompson, \& Froimson, 2015), which also portrays some level of authority. Physical coercion has been assessed in many studies but using different terms, such as harsh discipline (McKinney et al., 2011). In a study by McKinney et al. (2011), harsh discipline (i.e., the use of psychological or verbal aggression and forms of corporal punishment which is similar to the construct of physical coercion utilized for this study) was linked to elevations in adolescents' behavioral problems, depression, and psychological problems (McKinney et al., 2011). Specifically, authoritarian parenting that is characterized by high demandingness and usually accompanied by harsh discipline tends to lead to behavioral problems in adolescents (McKinney et al., 2011), resulting in a negative association with prosocial behavior (Hastings et al., 2006). However, parents who engage in these harsh discipline strategies, but inconsistently, their adolescents are more likely to engage in antisocial behaviors (Gryczkowski et al., 2018; Laible, Eye, \& Carlo, 2008). On the other hand, parents who use inductive discipline, characterized by conversing with their about how their actions can 


\section{PROSOCIAL BEHAVIORS}

influence others, is a predictor for empathetic and sympathetic actions related to prosocial behavior towards others (Gryczkowski et al., 2018; Laible et al., 2008).

Nonreasoning/punitive. The third dimension of authoritarian parenting that is utilized for this research is nonreasoning/punitive practice. This is characterized by punishment through harshness and allowing for no reasoning to their child about the punishment decided by the parent (Wu et al., 2002). This facilitates control over the child and one parent practice (or dimension) commonly associated with authoritarian parenting is control, which is linked to nonreasoning/punitive parenting. Control may take the form of psychological (Kokkinos \& Voulgaridou, 2016; Kuppens et al., 2013) or behavioral control (Kokkinos \& Ioanna, 2016; McKinney et al., 2011). Parental psychological control can be defined as the different behaviors carried out by parents in order gain authority over the thoughts and feelings of their adolescents, while behavioral control is the actions that parents partake in to gain power over their adolescents' actions and behaviors (Smetana et al., 2016; Yoo et al., 2013). McKinney et al. (2011) also explained that the relationship between adolescents and their parents, whom adolescents perceived as high in psychological control consisting of involved statements (e.g., express the parent's negative disapproval of their child's behavior), tends to be significantly negative, and less connectedness is present between the parties.

Previous studies have also reported a negative relationship between high control and discipline, associated with authoritarian parenting styles, and prosocial behaviors (Ruiz-Ortiz, Braza1, Carreras, \& Muñoz, 2017), and have found a positive relationship between authoritative parenting and antisocial behaviors. Gryczkowski et al. (2018) reported that when parents engaged in negative parenting practices that involve high parental control and discipline, this results in children's antisocial rather than prosocial behavior. In one study, Pinquart (2017), one 


\section{PROSOCIAL BEHAVIORS}

aim of the researchers was to assess whether authoritarian parenting highly predicts externalizing problems in children and teenagers. They found that parents who reported practices related to authoritarian parenting, specifically, their adolescents showed more negative behaviors characterized by aggression and delinquency (Pinquart, 2017), which are two externalizing behaviors that hinder prosocial behaviors (Padilla-Walker et al. 2012).

Prosocial behavior with friends versus strangers. Alongside prosocial behavior with parents, prosocial behaviors with strangers versus friends, vary significantly. With this study assessing how adolescents engage in prosocial behaviors with friends versus strangers, the expectation was that there will be a significant difference between the two groups. It was also expected that adolescents will engage in more prosocial behaviors with friends than strangers as individuals, especially adolescents are more likely to engage in prosocial behaviors with individuals that they know or have a strong relationship with versus those they do not know (Padilla-Walker et al., 2016). However, if adolescents do engage in prosocial behaviors with strangers, these acts are usually influenced by dispositional traits such as sympathy (PadillaWalker et al., 2016), or they expect something in return (Lewis, 2018). Therefore, it seems plausible that this study will produce similar results, in that prosocial behaviors with friends and strangers will have comparable associations with authoritarian parenting.

Padilla-Walker, Carlo, Christensen, and Yorgason (2012) explained that even though children exhibit positive and prosocial behaviors towards family members, the reactions from parents are positive, their actions towards strangers may not lead to similar results. Also, Carlo, Fabes, Laible, and Kupanoff (1999) assessed the social influence of parents/familiar individuals on young adolescents' prosocial behaviors. It was noted that even though there have been many types of research, though weak, on the relationship between parenting styles and practices on 


\section{PROSOCIAL BEHAVIORS}

prosocial development, they found that positive, supportive parenting significantly influences adolescents' prosocial development. The researchers also discussed the cycle of prosocial behavior. They reported that adolescents are prosocial towards peers when their peers are prosocial towards them. They explained that this exchange helps to improve their moral development.

Also, Padilla-Walker and Christensen (2010) examined the relationship between parenting and prosocial behaviors of adolescents between strangers, family, and friends. They reported that when there was positive parenting, which was characterized by warmth and involvement, adolescents were more prosocial towards their family members and friends, which is a way to maintain a close-knit. With friends versus strangers, it was also found that adolescents engaged in prosocial behaviors with their friends than with strangers (Padilla-Walker

\& Christensen, 2010; Padilla-Walker et al., 2012; Wentzel et al., 2018). Subsequently, adolescent dispositional factors such as empathy and self-regulation were also another reason for their prosocial behaviors towards friends (Padilla-Walker \& Christensen, 2010). Still, if the relational aspect such as the relationship quality with friends was assessed, the results might have shown otherwise.

\section{Control Variables}

Child reported reported sex, age in years, race/ethnicity, and family structure will be the control variables of this study. Controlling for gender-specific differences is important as results have shown that girls tend to be more prosocial than boys as girls are socialized and encouraged to be more caring and prosocial. In contrast, boys are socialized to be more masculine and suppressing of prosocial behaviors (Van der Graaff et al., 2018). Also, findings suggest that engagement in prosocial behaviors is higher during late than early adolescence (Padilla-Walker 


\section{PROSOCIAL BEHAVIORS}

et al., 2018; Van der Graaff et al., 2018). On the other hand, race/ethnic differences may influence the relationship between authoritarian parenting style and prosocial behaviors (Chang et al., 2018). As a result, these demographic predictors were included as control variables.

\section{The Current Study}

Many studies have revealed a strong negative relationship between authoritarian parenting style and adolescents' prosocial behavior. Therefore, for this study, it will be hypothesized that authoritarian parenting will predict lower levels of prosocial behaviors in adolescents. Therefore, when parents engage in authoritarian parenting style, their adolescents would less likely engage in prosocial behaviors. It was hypothesized that authoritarian parenting style/behaviors will be negatively associated with adolescents' prosocial behaviors with friends and strangers.

Parents have a significant impact on adolescents' prosocial behaviors. It has been shown that positive and responsive parenting practices/styles predict higher levels of prosocial behaviors in adolescents (Grusec \& Hastings, 2015; McKinney et al., 2011). Despite extensive research on authoritarian parenting styles on adolescents' prosocial behaviors in general, only little has examined these variables concerning friends and strangers. Therefore, this study aimed to explore the links between the authoritarian parenting style on adolescents' prosocial behaviors and how this is similar or differs from friends and strangers. It was hypothesized that the association between authoritarian parenting and prosocial behavior will be stronger for friends than for strangers. 
PROSOCIAL BEHAVIORS

\section{Chapter III}

\section{Method}

\section{Participants}

The participants of the study were a sample of 463 families taken from Wave $\mathrm{V}$ of the Flourishing Families Project (FFP). This included 311 two-parent families and 151 single-parent families. This longitudinal study was one that incorporated children participants between ages 13 and 18 . The average age of the children was 15.3 years $(S D=1.06$, range $=13-18)$. Maternal age was not assessed at Wave V, but at Wave II (i.e., the last wave in which it was measured), mothers' average age was 44.15 years $(S D=6.77$, range $=23-61)$. Regarding ethnicity, 66\% were European American, 12\% were African American, 1\% were Hispanic, and 1\% were Asian Americans. A total of $20 \%$ of families identified themselves as multi-ethnic, combining two or more ethnicities within their family. Parental education was also acquired. A total of $61 \%$ of mothers and approximately $70 \%$ of fathers reported having acquired a bachelor's degree or higher. For family income, $19.8 \%$ of families reported making less than $\$ 59,000 ; 19.8 \%$ reported earned income between $\$ 60,000-99,000 ; 22.8 \%$ reported $\$ 100,000-149,000$, and $16.2 \%$ reported making $\$ 150,000$ or more per year. In terms of relationship status, $29.8 \%$ of single parents reported being never-married, $46.4 \%$ divorced, $15.2 \%$ cohabiting, $4 \%$ widowed, and $4.6 \%$ not cohabiting but currently in a committed relationship.

\section{Procedures}

The participating families of the FFP were selected from a northwestern city. In the year of 2007, these families were interviewed for a consecutive eight months period for a Wave I data sample. The families were then interviewed yearly in 2008, 2009, 2010, and 2011, for the second, third, fourth, and fifth interview, respectively. The recruitment process involved a 


\section{PROSOCIAL BEHAVIORS}

database, Polk Directories/InfoUSA, which is a purchased national telephone survey database. It is reported that the Polk Directories consists of extensive household information (including presence and ages of children) for 82 million households across the United States. Families from these households were randomly selected based on socioeconomic and racial stratification that were similar to those of reports of local district schools identified. To be qualified to participate in this project, the families of these households must have a child between the ages 10 and 14 living within the target census area. With this, 692 families were qualified and contacted to participate in the project, and of these families, 423 agreed to participate. This showed a $61 \%$ response rate. Despite this moderate response rate, the Polk Directory national database was generated using the telephone, magazine, and internet subscription reports, which resulted in the underrepresentation of families of lower socioeconomic status in this response rate. To yield results more closely to the local district, some families were recruited outside the database. This included the use of referrals and fliers $(n=77,15 \%)$. This was done to increase the representation of the social-economic and ethnic diversity of the sample.

A multi-stage protocol was used to contact and recruit families. Initially, an introductory letter of the study was sent with possibly qualified families (this progression was skipped for the 77 families who responded to fliers). Subsequently, interviewers conducted home visits and made telephone calls to affirm qualification to take part in the study. When eligibility and consent were confirmed for the families that will participate in the study, an appointment was scheduled by the interviewers to make necessary arrangements to visit the families' home to conduct an assessment through video-taped associations and in-home questionnaires. For those families who refused to participate in the study, the universal reason explained was their time constraints and privacy concerns. It is essential to note that little information was missing. As a 


\section{PROSOCIAL BEHAVIORS}

process of eliminating analytical drawbacks, questionnaires from the in-home interviews were screened for missing answers, and double marking.

\section{Measures}

Demographic controls. The participants reported their age, gender $(0=$ male, $1=$ female), family structure ( 0 = single-parent family, 1 = 2-parent married family), and ethnicity. Concerning ethnicity, the original codes were recoded as there were too little individuals in some groups, so dummy codes were created to multiple groups: Black $(0=$ not Black, $1=$ Black $)$, and all other $(0$ = not all other, 1 = Hispanic, Asian American, Multiethnic) (see Appendix A).

Authoritarian parenting styles. Mothers reported their parenting behaviors and styles, which were measured using the Parenting Styles and Dimensions Questionnaire-Short Version (PSDQ; Robinson, Mandleco, Olsen, \& Hart, 2001) provided in detail in Appendix B. The items of this measure assessed mothers' behaviors that closely mirrors authoritarian parenting style. Mothers responded to questions which assessed the frequency of the three subscales of authoritarian parenting styles: physical coercion (4 items, e.g., "Use physical punishment as a way of disciplining my child"), verbal hostility (4 items, e.g., "Yell or shout when my child misbehaves") and nonreasoning/punitive (4 items, e.g., "Punish by taking privileges away from my child with little if any explanations"). Responses were rated using a five-point Likert-type

scale, which ranged from 1 (never) to 5 (always). Scale scores were calculated using the means of the parenting styles. Higher scores were an indicator of higher levels of one of the three parenting styles and/or specific dimensions of parenting behavior listed above. The scale demonstrated good internal consistency (Cronbach's $\alpha=.82$ ).

Adolescents' prosocial behavior towards friends and strangers. Adolescents reported their prosocial behavior by answering items of the 18-item Inventory of Strengths (Peterson \& 


\section{PROSOCIAL BEHAVIORS}

Seligman, 2004), outlined in Appendix C. These items were used to identify interpersonal strength, specifically in how adolescents' actions portrayed prosocial behaviors toward others/strangers (9 items, a modified version of the Peterson and Seligman original measure), and prosocial behavior directed toward friends ( 9 items created for this study). Their responses ranged from 1 (not like me at all) to 5 (very much like me). This five-point Likert scale consisted of items that assessed how much they disagreed or agreed with statements about themselves relating to prosocial behaviors towards friends (9 items, e.g., "I voluntarily help my neighbors") and strangers/others (9 items, e.g., "I help people I don't know, even if it is not easy for me”). Scale scores were calculated using the means of the prosocial behavior towards friends and strangers. High scores accumulated from these items indicated that these adolescents were more likely to be benevolent and generous towards outsiders/strangers, family, and friends. The scale demonstrated good internal consistency for friends (Cronbach's $\alpha=.93$ ) and strangers (Cronbach's $\alpha=.86)$.

\section{Analysis Plan}

Preliminary analyses included descriptive statistics, bivariate correlations, and ANOVAs to explore mean differences in prosocial behavior and authoritarian parenting by gender and family structure. The primary hypothesis is that when parents engage in highly authoritarian parenting, their adolescents' will less likely engage in prosocial behaviors with friends and strangers. This hypothesis was tested in two regressions (i.e., one for prosocial behaviors with friends and one for prosocial behaviors with strangers). Each included the four control variables (i.e., child sex, age, race/ethnicity, and family structure) on the first step of the regression, and authoritarian parenting was added on the second step of the regression. 


\section{Chapter IV}

\section{Results}

\section{Preliminary Analyses}

Descriptive statistics. Descriptive statistics are provided in Table 1.

Correlations. Correlations were conducted to assess the relationships between the control variables and authoritarian parenting styles and prosocial behaviors towards friends and strangers (see Table 2). Age was not significantly related to adolescents' engaging in prosocial behaviors towards friends and strangers, or with maternal authoritarian parenting. Gender was associated with maternal authoritarian parenting style and prosocial behaviors towards friends and strangers. Notably, results showed that mothers were more likely to be authoritarian in their parenting style with boys than girls.

In contrast, these analyses also revealed that girls showed higher scores in their engagement in prosocial behaviors towards friends and strangers. Ethnicity was also negatively related to family structure and maternal authoritarian parenting style, and adolescents' engagement in prosocial behaviors towards friends and strangers. African American youth were less likely to be two-parent family households than were their peers of other ethnicities. Additionally, African American mothers were more likely to be authoritarian in their parenting style than were the mothers of the youths of all other ethnicities. African American teens were also less likely to engage in prosocial behaviors with friends and strangers than were non-Black peers. A positive correlation was evident between other ethnicities and authoritarian parenting, but this relationship was not significant. Mothers with Asian American, Hispanic, and Multiethnic ethnicity were authoritarian in their parenting style. Additionally, a negative but nonsignificant relationship was present between individuals from all other ethnicities and prosocial 


\section{PROSOCIAL BEHAVIORS}

behaviors with friends and strangers. Teens from other ethnicities reported low levels of prosocial behaviors with friends and strangers, but this relationship was also nonsignificant. Additionally, highly authoritarian mothers had adolescents who reported lower prosocial behaviors with friends and a slight difference with strangers. Results from correlations for family structure also revealed that parents from two-parent families had adolescents who were highly authoritarian had adolescents who had lower levels of prosocial behaviors towards friends. Conversely, parents from two-parent families had adolescents who showed higher levels of prosocial behaviors towards strangers. Also, high levels of the authoritarian parenting style were related to adolescents' low levels of prosocial behaviors with friends but not with strangers. Prosocial behaviors towards friends were also associated with prosocial behaviors toward strangers. In particular, adolescents who were highly prosocial towards friends were also highly prosocial towards strangers.

ANOVAs. In relation to authoritarian parenting and gender, mothers engaged in highly authoritarian parenting with boys $(M=1.61, S D=0.37)$ than they did with girls $(M=1.54, S D=$ $0.37), F(1,456)=3.92, p<.05$. This analysis revealed group mean differences for gender in relation to prosocial behavior with friends, $F(1,458)=53.52, p<.001$. Girls $(M=4.54, S D=$ $0.45)$ reported higher levels than did boys $(M=4.16, S D=0.64)$. In terms of gender differences, the ANOVA for prosocial behavior with strangers revealed significant group mean differences, $F(1,458)=17.77, p<.001$. Girls $(M=3.40, S D=0.74)$ reported higher levels than did boys $(M$ $=3.11, S D=0.69$ ).

In terms of differences by family structure, the ANOVA for prosocial behavior with strangers revealed significant group mean differences, $F(1,458)=4.68, p<.05$. Adolescents from two-parent family structures $(M=3.31, S D=0.70)$ reported higher levels of prosocial 


\section{PROSOCIAL BEHAVIORS}

behaviors than adolescents in one parent family structures $(M=3.16, S D=0.77)$. Additionally, no group differences were evident for prosocial behaviors with friends, $F(1,458)=0.18, p=.68$. Adolescents in one parent families $(M=4.38, S D=0.54)$ reported mathematically equal levels of prosocial behaviors with friends than did adolescents in two parent families $(M=4.35, S D=$ $0.60)$.

Concerning authoritarian parenting styles, group mean differences were also reported and significant for family structure, $F(1,456)=3.94, p<.05$. Adolescent children who lived in single parent families reported higher levels of authoritarian parenting $(M=1.63, S D=0.40)$ than did youth in two-parent married families $(M=1.55, S D=0.35)$.

\section{Hypothesis Testing}

Prosocial behavior with friends. Firstly, a linear regression was used to assess the relationship of prosocial behaviors towards friends, by accounting for the influence of the control variables on the first and then adding authoritarian parenting on the second step to assess its influence (see Table 3). The set of variables explained a significant portion of the variance in prosocial behaviors with friends on step $1, F(5,442)=17.49, p<.001, R^{2}=.17$. There was no effect on child age, but European American teens reported higher levels of prosocial behavior with friends than did their African American peers or agemates from other ethnic groups. Girls reported higher levels of prosocial behavior than did boys. Unexpectedly, teens in two-parent households reported lower levels of prosocial behavior. Still, this effect was a suppressor effect, which was due to controlling for ethnicity (i.e., the association disappeared if the dummy code for African American ethnicity was removed). At second step, the inclusion of authoritarian parenting style explained no additional variance in prosocial behavior with friends, $\Delta F(1,441)=$ $1.03, p<.001, \Delta R^{2}=.002$. The associations for the control variables were the same as in the 


\section{PROSOCIAL BEHAVIORS}

first step.

Prosocial behavior with strangers. Secondly, the same type of linear regression was also utilized for prosocial behaviors with strangers (see Table 4). On Step 1, the variables explained a significant portion of variance in adolescents' prosocial behaviors with strangers, $F(5,442)=5.63, p<.001, R^{2}=.06$. There was no effect evident for child's age. African American teens reported lower levels of prosocial behaviors with strangers than peers of other ethnicities. Additionally, gender was significantly related to prosocial behaviors with strangers. In particular, girls reported higher levels of prosocial behaviors with strangers than boys. For family structure, no associations were present between teens in single-parent and two-parent family households and their engagement in prosocial behaviors towards strangers. When maternal authoritarian parenting was included in the second step, no association was found between authoritarian parenting style and adolescents' prosocial behaviors towards strangers, $\Delta F(1,441)=0.12, p<.001, \Delta R^{2}=.000$. Therefore, the addition of authoritarian parenting did not predict adolescents' engagement in prosocial behaviors with strangers. The associations for the control variables were the same as the first step. 
PROSOCIAL BEHAVIORS

\section{Chapter V}

\section{Discussion}

It is important to study and understand prosocial behaviors in adolescence as this is a period of developmental changes necessary in understanding others' feelings and opinions through engagement with distinct relationships such as friends and strangers (Hastings et al., 2016). Parenting has previously been associated with adolescents' prosocial behaviors (Van def Graaff et al., 2018). The aim of this study was to investigate if there was a negative relationship between maternal authoritarian parenting and prosocial behaviors. Secondly, it was also intended to examine whether the relationship between maternal authoritarian parenting style and adolescents' prosocial behaviors would be stronger for friends than for strangers. It was found that maternal authoritarian parenting was associated with adolescents' engagement in prosocial behaviors towards friends but not strangers, but this was in the correlation only (i.e., the association was not present in the regression). This finding highlights the idea that there is a relationship between these variables, but it was explained by the inclusion of control variables in the regression. Additionally, no support was found for authoritarian parenting and adolescents' prosocial behaviors towards strangers in the correlation or regression analysis. Collectively, the results of this study gave an overall mixed relationship between authoritarian parenting and adolescents' prosocial behaviors towards friends and strangers. The discussion and interpretations of these findings are at length below.

\section{Interpretation of Findings}

The analyses showed that these hypotheses were partially supported. More specifically, for hypothesis 1 , which was that authoritarian parenting style/behaviors will be negatively associated with adolescents' prosocial behaviors with friends and strangers, correlations showed 


\section{PROSOCIAL BEHAVIORS}

a relationship between authoritarian parenting and adolescents' prosocial behaviors towards friends but not strangers. However, the regression revealed no association for friends or for strangers. This null effect finding was inconsistent with previous literature that parents who engage in coercion, control, and demandingness, which is associated with authoritarian parenting, had children who were incapable of controlling negative emotions (Wang, 2019). This leads to inability to self-regulate, which is necessary for successful engagement in prosocial behaviors (Memmott-Elison, Padilla-Walker, Yorgason, \& Coyne, 2020; Wang, 2019). Similar to this, when looking at emotional responses, authoritarian parenting characterized by punitive practices such as harsh and non-negotiating responses are related to youths' lesser engagement in prosocial behaviors (McKinney et al., 2011). For example, these punitive practices may lead children to fear their parents, hence, suppressing their feelings, especially negative emotions, which leads to disengagement with others (Spinrad, 1999). Therefore these youth may be less likely to be prosocial with others.

As discussed above, there were limited prior studies on the associations between the overarching authoritarian style of adolescents' prosocial behaviors towards friends and strangers. These findings, in conjunction with the absence of evidence, suggest a publication bias in this area (i.e., the "file drawer problem"), where studies with statistically significant results are given greater recognition than those with small significance. This null association could be the reflection of other variables or factors that are more determinant of the relationship between authoritarian parenting and adolescents' prosocial behaviors with friends and strangers. For example, the study by Carlo et al. (2007) revealed that although there was an association between specific parenting styles and adolescents' prosocial behaviors, a third variable was responsible for this association, specifically children's sympathy. In particular, when parents 


\section{PROSOCIAL BEHAVIORS}

engage in conversations about prosocial behaviors with their adolescents, there were more likely to produce these behaviors with others. However, the findings showed that this might be due to teen's sympathy as they developed empathic concerns and a greater sense of the impact of their actions towards others. Therefore, parents who may use authoritarian parenting characterized by verbal hostility, such as screaming and the use anger and psychological control to improve or force teens to engage in lower social and emotional adjustment (McKinney et al., 2011). This will negatively impact teens engagement in prosocial behaviors as they will become less able to control and understand their emotions which will impede their understanding of others' emotions which is necessary for the engagement in prosocial behaviors (Eisenberg et al., 2015; McKinney et al., 2011). Thus, for future studies, it may be informative to consider adolescents' sympathy and empathy as potential intermediaries between authoritarian parenting and prosocial behaviors in adolescence.

For the second hypothesis, I anticipated that the association between authoritarian parenting and prosocial behavior would be stronger for friends than for strangers. Correlations revealed that highly authoritarian mothers had adolescents who engaged in less prosocial behaviors with friends but not with strangers. This finding supports the concept that mothers who engage in physical coercion, verbal hostility, and nonreasoning/punitive behaviors provide a platform for children to ineffectively engage in positive interactions with others. On the other hand, the regression analyses revealed no associations between authoritarian parenting and adolescents' prosocial behaviors towards friends or strangers. This is a result of regression analyses incorporating a variety of factors, that is, the control variables, which may be increasingly important to consider assessing the relationship between authoritarian parenting and adolescents' prosocial behaviors towards friends and strangers. 


\section{PROSOCIAL BEHAVIORS}

\section{Control Variables}

Inconsistent with studies that found older adolescents to be more prosocial than younger adolescents (Padilla-Walker et al., 2018; Van der Graaff et al., 2018), there was no effect for age on adolescents' prosocial behaviors towards friends and strangers. Inconsistent with previous studies, age showed no association with adolescents' engagement in prosocial behaviors towards friends and strangers. This is surprising, as studies have indicated as children (adolescents) get older, physical and brain maturity increases, which increases their understanding of other's feelings and emotions, and therefore allowing them to be more prosocial with others (Van der Graff et al., 2018).

Consistent with previous studies, correlations and regressions indicated that girls showed higher scores in their engagement in prosocial behaviors towards friends and strangers. This may stem from girls being socialized to be nicer or more empathic towards others than boys (Carlo, Raffaelli, Laible, \& Meyer, 1999). Regarding ethnicity, analyses from correlations and regressions revealed that European American teens reported higher levels of prosocial behavior with friends and strangers than did their African American peers or agemates from other ethnic groups. This corresponds with findings from studies that show European Americans reporting higher levels of prosocial behaviors with friends and strangers than African Americans (Belgrave et al., 2011). European American children are more likely to be socially competent (Nelson et al., 2013), which is necessary for engaging in prosocial behaviors (Hartup \& van Lieshout, 1995). In contrast, African American parents encourage their children to suppress their negative emotionality, which may lead them to shy away from prosociality (Nelson et al., 2013). Other studies have reported that European American teens engage in more prosocial behaviors (e.g., altruism and compliant helping) with others than other ethnicities, specifically Mexican 


\section{PROSOCIAL BEHAVIORS}

American teens (Carlo, Knight, McGinley, Zamboanga, \& Jarvis, 2010). However, other studies have shown that European American teens, rather than African American teens, reported higher levels of prosocial behaviors towards friends and strangers (Padilla-Walker et al., 2017). The reason behind this might be due to different cultures possessing different meanings and values over differing behaviors. That African American adolescents are less prosocial than those from other ethnic groups is interesting from a racial/ethnic perspective, as it suggests that African American teens might be less cautious about engaging in prosocial behaviors with strangers from other ethnic groups. This may be a result of parental armoring as part of racial-ethnic socialization (DiAquoi, 2017; Edmondson Bell \& Nkomo, 1998).

Upon analysis, it was expected when assessing family structure, two-parent households would have a positive association with adolescents' prosocial behaviors towards friends and strangers. However, a suppressor effect occurred within the regression, which revealed that teens in two-parent households reported lower levels of prosocial behavior when ethnicity was controlled. African American teens were disproportionately less likely to live in two-parent households than were their peers from other ethnic groups. A supplemental analysis indicated that this effect of family structure disappeared if ethnicity was not controlled in the regression. This suppressor effect should be viewed with caution as it may be an anomaly in the present dataset.

\section{Limitations}

There were a variety of findings within this study. Correlations revealed a negative relationship between authoritarian parenting and adolescents' prosocial behaviors towards friends and not strangers, but regression analyses showed no association for friends or for strangers. Correlations also revealed that authoritarian mothers had adolescents who engaged in 


\section{PROSOCIAL BEHAVIORS}

less prosocial behaviors with friends but not strangers, and regression analyses also showed no association between engaging in less or more prosocial behaviors with these distinct relationship groups. Although these informative findings were presented, there are some limitations to consider when interpreting the overall findings of this study. Firstly, the study sample was composed of mainly European American teens, which may limit the generalizability of the findings to teens from other ethnic groups. Therefore, the conclusion is to consider assessing the relationship between maternal authoritarian parenting style and adolescents' prosocial behaviors within family households such as African American and Asian American groups (Dornbusch, Ritter, Leiderman, Roberts, \& Fraleigh, 1987) that would be at risk for authoritarian parenting to allow for a comparatively normal distribution between the variables.

Another limitation may concern that all measures yielded self-report results, with mothers indicating their engagement in the three subdimensions of authoritarian parenting and with adolescents reporting their prosocial behaviors towards friends and strangers. There is potential for bias, with parents underreporting their authoritarian practices and teens overreporting their prosocial behaviors through positive self-bias (Paulhus, 1986), which may also differ by age and gender of teen and other factors such as parental stress (Moens, Weeland, Van der Giessen, Chhangur, \& Overbeek, 2018). Therefore, as a future consideration, researchers may wish to set up scenarios to observe and collect information on how parents are authoritarian in their parenting and how adolescents are prosocial with friends versus strangers (Skinner, MacKenzie, Haggerty, Hill, \& Roberson, 2011). This study focused on the overarching authoritarian parenting style with three specific subdimensions (i.e., physical coercion, verbal hostility, and nonreasoning/punitive strategies). However, there are other subdimensions associated with authoritarian parenting that could also yield interesting findings. For example, love withdrawal, 


\section{PROSOCIAL BEHAVIORS}

characterized by highly punitive, power assertive but nonphysical behaviors, has been found to be associated with isolation in children, which can lead to inhibition of prosocial behaviors with others (Hinde \& Groebel, 1991). However, it is important to note that even though these results were presented, the mean for authoritarian parenting was moderately low, indicating that on average, youth in this sample had limited experience with these practices. Additionally, physical coercion in authoritarian parenting might be low or irrelevant to disciplining adolescents compared to younger children. Reflecting on this, Moilanen et al. (2014) revealed that this subdimension loaded modestly on a latent authoritarian parenting factor at Waves III and IV in the same dataset; verbal hostility and nonreasoning loaded more strongly in comparison on this factor. In this analysis, the mean for physical coercion was the lowest of the three dimensions, and nonreasoning was most strongly associated with prosocial behaviors (see Appendix D). Therefore, compelling results were present, but the influence of authoritarian parenting on adolescents' prosocial behaviors may be a reflection of other factors to consider.

\section{Future Directions}

The results of these analyses could lean towards future studies focusing on smaller combinations of parenting practices associated with authoritarian parenting to better understand their influence on adolescents' prosocial behaviors toward friends and strangers. For example, rather than assessing a combination of three parenting practices associated with authoritarian parenting to understand its effects on prosocial behaviors, researchers could assess these practices individually or in pairs to assess moderation. More particularly, one could examine if both practices together are worse than one or the other by itself (e.g., verbal hostility and physical coercion, nonreasoning/punitive and physical coercion, and so on). 


\section{PROSOCIAL BEHAVIORS}

Additionally, future work could benefit from the use of a more equivalent measure as it is uncertain whether the present study's measure of authoritarian parenting functions similarly across ethnic groups, and this is important to establish as authoritarian parenting is viewed differently across groups. Parenting characterized by spanking, which is a form of physical coercion also associated with authoritarian parenting, is viewed as a sign of love from parents by African American adolescents (Lansford, Deater-Deckard, Dodge, Bates, \& Pettit, 2004) than do European American teens. With this, many measures have viewed and presented this form of physical punishment in the light as physical abuse rather than as love through discipline (Lansford et al., 2004).

A second potential explanation relates to measurement. Similar to the above point about the measure of authoritarian parenting, the degree to which the current study's measure of prosocial behavior is equivalent across ethnic groups is unknown. This may explain the demonstrated ethnic differences in these analyses. Further, the current study was limited in that the measure of prosocial behavior was limited to peers and strangers. Thus, another future direction is to include a measure of prosocial behavior towards family members. One idea can be raised as it regards to African American teens, in particular, is how family plays an integral role in their community. For example, children are expected, especially females, to be highly connected to the well-being of the family (Hammack, Robinson, Crawford, \& Li, 2004). Therefore, nice and prosocial behaviors are expected from each member, and consequently effective measures assess these expectations and interactions may lead to interesting findings of prosocial behaviors towards family members.

Findings suggest that African American adolescents are less prosocial than those from other ethnic groups. This finding is interesting from a racial/ethnic perspective as the results 


\section{PROSOCIAL BEHAVIORS}

indicated that African American teens might be cautious about engaging in prosocial behaviors with one group versus another. Additionally, assessing ethnicity as a moderator rather than a control variable influencing the relationships between authoritarian parenting and prosocial behaviors will more directly explain if/when, the strength of, and under what circumstances that these relationships exist which will give a more profound understanding about what is so unique about ethnicity to yield these results.

\section{Conclusions \& Implications}

There is no doubt that authoritarian parenting and adolescents' prosocial behaviors towards friends and strangers, provide an understanding of how people, specifically parents, influence behaviors. The findings from this study could provide many pathways for clinical implications for parents and those who work with families. Specifically, the findings indicate that parents may not have to completely dismiss the use of authoritarian parenting style as it did not portray the "all bad" status that previous studies have imprinted on it. However, these results should be welcomed while using circumspection as the study focused on the overarching authoritarian parenting style rather than its dimensions. Additionally, programs could utilize this information to understand that one must consider multiple factors that can influence adolescents' prosocial behaviors towards friends and strangers and counsel parents accordingly. Intervention programs could use information from this study to assist parents in accomplishing this by promoting having parents analyze their parenting and envision how they see their style as an inhibitor or facilitator for their child's prosocial behaviors. 
PROSOCIAL BEHAVIORS

\section{References}

Bates, J. E., \& Pettit, G. S. (2015). Temperament, parenting, and social development. In J. E. Grusec \& P. D. Hastings (Eds.), Handbook of socialization: Theory and research (pp. 372-397). New York, NY: Guilford Press.

Barry, C. M., Padilla-Walker, L. M., Madsen, S. J., \& Nelson, L. (2008). The impact of maternal relationship quality on emerging adults' prosocial tendencies: Indirect effects via regulation of prosocial values. Journal of Youth and Adolescence, 37, 581-591.

Baumrind, D. (1966). Effects of authoritative parental control on child behavior. Child Development, 37, 887-907.

Baumrind, D. (1971). Current patterns of parental authority. Developmental Psychology, 4, 1103.

Baumrind, D. (1973). The development of instrumental competence through socialization. In A. D. Pick (Ed.), Minnesota symposium on child psychology (pp. 3-46). Minneapolis, MN: University of Minnesota Press.

Baumrind, D. (1987). A developmental perspective on adolescent risk-taking in contemporary America. New Directions for Child Development, 37, 93-125.

Baumrind, D (1991). The influence of parenting style on adolescent competence and substance use. The Journal of Early Adolescence, 11, 56-95.

Belgrave, F. Z., Nguyen, A. B., Johnson, J. L., \& Hood, K. (2011). Who is likely to help and hurt? Profiles of African American adolescents with prosocial and aggressive behavior. Journal of Youth and Adolescence, 40, 1012-1024.

Card, N. A., Sawalani, G. M., Stucky, B. D., \& Little, T. D. (2008). Direct and indirect aggression during childhood and adolescence: A meta-analytic review of gender 


\section{PROSOCIAL BEHAVIORS}

differences, intercorrelations, and relations to maladjustment. Child Development, 79, 1185-1229.

Carlo, G., Fabes, R. A., Laible, D., \& Kupanoff, K. (1999). Early adolescence and prosocial/moral behavior II: The role of social and contextual influences. Journal of Early Adolescence, 19, 133-147.

Carlo, G., McGinley, M., Hayes, R., Batenhorst, C., \& Wilkinson, J. (2007). Parenting styles or practices? Parenting, sympathy, and prosocial behaviors among adolescents. The Journal of Genetic Psychology, 168, 147-176.

Caprara, G. V., Kanacri, B. P.L., Zuffiano, A., Gerbino, M., \& Pastorelli, C. (2015). Why and how to promote adolescents' prosocial behaviors: Direct, mediated and moderated effects of the CEPIDEA school-based program. Journal of Youth and Adolescence, 44, 22112229.

Chang, L. (2003). Variable Effects of children's aggression, social withdrawal, and prosocial leadership as functions of teacher beliefs and behaviors. Child Development, 74, 535-548.

Chen, L., Chen, X., Zhao, S., French, D. C., Jin, S., \& Li, L. (2018). Predicting substance use and deviant behavior from prosociality and sociability in adolescents. Journal of Youth and Adolescence, 48, 744-752.

Chang, L., Giunta, L. D., Oburu, P., Skinner, A. T., Tapanya, S., Zelli, A., ... Bacchini, D. (2018). Parental acceptance-rejection and child social behavior: Developmental transactions across the transition to adolescence in nine countries, mothers and fathers, and girls and boys. Developmental Psychology, 54, 1881-1890.

de Guzman, M. R. T., \& Carlo, G. (2004). Family, peer, and acculturative correlates of prosocial development among Latinos. Great Plains Research, 14, 185-202. 


\section{PROSOCIAL BEHAVIORS}

DiAquoi, R. (2017). Symbols in the strange fruit seeds: What "the talk" Black parents have with their sons tells us about racism. Harvard Educational Review, 87, 512-537.

Dornbusch, S. M., Ritter, P. L., Leiderman, P. H., Roberts, D. F., \& Fraleigh, M. J. (1987). The relation of parenting style to adolescent school performance. Child Development, 58, 1244-1257.

Edmondson Bell, E. L. J. E., \& Nkomo, S. M. (1998). Armoring: Learning to withstand racial oppression. Journal of Comparative Family Studies, 29, 285-295.

Eisenberg, N., Guthrie, I. K., Cumberland, A., Murphy, B. C., Shepard, S. A., Zhou, Q., \& Carlo, G. (2002). Prosocial development in early adulthood: A longitudinal study. Journal of Personality and Social Psychology, 82, 993-1006.

Eisenberg, N., Spinrad, T. L., \& Knafo-Noam, A. (2015). Prosocial development. In M. E. Lamb \& R. M. Lerner (Eds.), Handbook of child psychology and developmental science: Socioemotional processes., Vol. 3, 7th ed. (pp. 610-656). Hoboken, NJ: Wiley.

Gryczkowski, M., Jordan, S. S., \& Mercer, S. H. (2018). Moderators of the relations between mothers' and fathers' parenting practices and children's prosocial behavior. Child Psychiatry and Human Development, 49, 409-419.

Hammack, P. L., Robinson, W. L., Crawford, I., \& Li, S. T. (2004). Poverty and depressed mood among urban African American adolescents: A family stress perspective. Journal of Child and Family Studies, 13, 309-323.

Hastings, P. D., Miller, J. G., \& Troxel, N. R. (2015). Making good: The socialization of children's prosocial development. In J. E. Grusec \& P. D. Hastings (Eds.), Handbook of socialization: Theory and research (pp. 637-660). New York, NY: Guilford Press.

Hay, D. F. (1979). Cooperative interactions and sharing between very young children and their 


\section{PROSOCIAL BEHAVIORS}

parents. Developmental Psychology, 15, 647-653.

Hinde, R., \& Groebel, J. (1991). Cooperation and prosocial behavior. Cambridge University Press.

Houltberg, B. J., Morris, A. S., Cui, L., Henry, C. S., \& Criss, M. M. (2016). The role of youth anger in explaining links between parenting and early adolescent prosocial and antisocial behavior. The Journal of Early Adolescence, 36, 297-318.

Ishak, Z., Low, S. F., \& Lau, P. L. (2012). Parenting style as a moderator for students' academic achievement. Journal of Science Education and Technology, 21, 487-493.

Jabeen, F., Anis-ul-Haque, M., \& Riaz, M. N. (2013). Parenting styles as predictors of emotion regulation among adolescents. Pakistan Journal of Psychological Research, 28, 85-105.

Kawabata, Y., Alink, Wan-Ling Tseng, W. L., van IJzendoorn, M. H., \& Crick, N. R (2011). Maternal and paternal parenting styles associated with relational aggression in children and adolescents: A conceptual analysis and meta-analytic review. Developmental Review, $31,240-278$.

Kokkinos, C. M., \& Voulgaridou, I. (2016). Links between relational aggression, parenting, and personality among adolescents. European Journal of Developmental Psychology, 14, 249-264.

Kuppens, S., Laurent, L., Heyvaert, M., \& Onghena, P. (2013). Associations between parental psychological control and relational aggression in children and adolescents: A multilevel and sequential meta-analysis. Developmental Psychology, 49, 1697-1712.

Laible, D., Eye, J., \& Carlo, G. (2008). Dimensions of conscience in mid-adolescence: Links with social behavior, parenting, and temperament. Journal of Youth and Adolescence, 37, $875-887$. 


\section{PROSOCIAL BEHAVIORS}

Laible, D., Thompson, R. A., \& Froimson, J. (2015). Early socialization: The influence of close relationships. In J. E. Grusec \& P. D. Hastings (Eds.), Handbook of socialization: Theory and research (pp. 35-59). New York, NY: Guilford Press.

Lansford, J. E., Deater-Deckard, K., Dodge, K. A., Bates, J. E., \& Pettit, G. S. (2004). Ethnic differences in the link between physical discipline and later adolescent externalizing behaviors. The Journal of Child Psychology and Psychiatry, 45, 801-812.

Lewis, M. (2018). Prosocial behavior. In T. K. Shackelford \& V. Weeks-Shackelford (Eds.), Encyclopedia of evolutionary psychological sciences (pp. 1-6) New York, NY: Springer.

Maccoby, E. E. (2015). Historical overview of socialization research and theory. In J. E. Grusec \& P. D. Hastings (Eds.), Handbook of socialization: Theory and research (pp. 3-32). New York, NY: Guilford Press.

McKinney, C., Milone, M. C., \& Renk, K. (2011). Parenting and late adolescent emotional adjustment: Mediating effects of discipline and gender. Child Psychiatry and Human Development, 42, 463-481.

Memmott-Elison, M., Padilla-Walker, L. M., Yorgason, J. B., \& Coyne, S. M. (2020). Intraindividual associations between intentional self-regulation and prosocial behavior during adolescence: Evidence for bidirectionality. Journal of Adolescence, 80, 29-40.

Mesurado, B. \& Richaud, M. C. (2017). The relationship between parental variables, empathy, and prosocial-flow with prosocial behavior toward strangers, friends, and family. Journal of Happiness Studies, 18, 843-860.

Milevsky, A. (2018). Parenting styles. In R. J. R. Levesque (Ed.), Encyclopedia of adolescence ( $2^{\text {nd }}$ ed., pp. 2706-2709). New York, NY: Springer.

Moilanen, K. L., Rasmussen, K. E., \& Padilla-Walker, L. M. (2014). Bidirectional associations 


\section{PROSOCIAL BEHAVIORS}

between self-regulation and parenting styles in early adolescence. Journal of Research on Adolescence, 25, 246-262.

Moens, M. A., Weeland, J., Van der Giessen, D., Chhangur, R. R., \& Overbeek, G. (2018). In the eye of the beholder? Parent-observer discrepancies in parenting and child disruptive behavior assessments. Journal of Abnormal Child Psychology, 46, 1147-1159.

Mounts, N. S. (2011). Parental management of peer relationships and early adolescents' social skills. Journal of Youth and Adolescence, 40, 416-427.

Nelson, J. A., Leerkes, E. M., Perry, N. B., O’Brien, M., Calkins, S. D., \& Marcovitch, S. (2013). European American and African American mothers' emotion socialization practices relate differently to their children's academic and social-emotional competence. Social Development, 22, 485-498.

Padilla-Walker, L. (2007). Characteristics of mother-child interactions related to adolescents' positive values and behaviors. Journal of Marriage and Family, 69, 675-686.

Padilla-Walker, L., Carlo, G., \& Memmott-Elison, M. K. (2017). Longitudinal change in adolescents' prosocial behavior toward strangers, friends, and family. Journal of Research on Adolescence, 28, 698-710.

Padilla-Walker, L., Carlo, G., Christensen, K., \& Yorgason, J. B. (2012). Bidirectional relations between authoritative parenting and adolescents' prosocial behaviors. Journal of Research on Adolescence, 22, 400-408.

Padilla-Walker, L., Carlo, G., \& Nielson, M. G. (2015). Does helping keep teens protected? Longitudinal bidirectional relations between prosocial behavior and problem behavior. Child Development, 86, 1759-1772.

Padilla-Walker, L. \& Christensen, K. J. (2010). Empathy and self-regulation as mediators 


\section{PROSOCIAL BEHAVIORS}

between parenting and adolescents' prosocial behavior toward strangers, friends, and family. Journal of Research on Adolescence, 21, 545-551.

Padilla-Walker, L. M., Memmott-Elison, M. K., \& Coyne, S. M. (2018). Associations between prosocial and problem behavior from early to late adolescence. Journal of Youth and Adolescence, 47, 961-975.

Padilla-Walker, L., Nielson, M. G., \& Day, R. D. (2016). The role of parental warmth and hostility on adolescents' prosocial behavior toward multiple targets. Journal of Family Psychology, 30, 331-340.

Paulhus, D. L. (1986). Self-deception and impression management in test responses. In A. Angleitner \& J. S. Wiggins (Eds.), Personality assessment via questionnaire (pp. 143165). New York, NY: Springer-Verlag.

Peterson, C., \& Seligman, M. E. P. (2004). Character strengths and virtues: A handbook and classification. New York, NY: Oxford University Press.

Pinquart, M. (2017). Associations of parenting dimensions and styles with externalizing problems of children and adolescents: An updated meta-analysis. Developmental Psychology, 53, 873-932.

Robinson, C. C., Mandleco, B., Olsen, S. F., \& Hart, C. H. (2001). The parenting styles and dimension questionnaire (PSDQ). In J. Touliatos \& B. Perlmutter (Eds), Handbook of family measurement techniques (pp. 319-321). Thousand Oaks, CA: Sage.

Romano, E., Tremblay, R. E., Boulerice, B., \& Swisher, R. (2005). Multilevel correlates of childhood physical aggression and prosocial behavior. Journal of Abnormal Child Psychology, 33, 565-578.

Ruiz-Ortiz, R., Braza1, P., Carreras, R., \& Muñoz, J. M. (2017). Differential effects of mother's 


\section{PROSOCIAL BEHAVIORS}

and father's parenting on prosocial and antisocial behavior: Child sex moderating. Journal of Child Family and Studies, 26, 2182-2190.

Schacter, H. L., \& Margolin, G. (2018). When it feels good to give: Depressive symptoms, daily prosocial behavior, and adolescent mood. Emotion, 5, 923-927.

Shaffer, D. R. (2009). Social and personality development (6th ed.). Belmont, CA: Wadsworth.

Shin, H. (2017). Friendship dynamics of adolescent aggression, prosocial behavior, and social status: The moderating role of gender. Journal of Youth and Adolescence, 46, 2305-2320.

Sim, T. N., \& Chin, J. E. H. (2014). Do mothers' and fathers' authoritative and authoritarian parenting interact? An exploration of schooling aspects with a Singapore adolescent sample. Youth \& Society, 46, 286-300.

Skinner, M. L., MacKenzie, E. P., Haggerty, K. P., Hill, K. G., \& Roberson, K. C. (2011). Observed parenting behavior with teens: Measurement invariance and predictive validity across race. Cultural Diversity and Ethnic Minority Psychology, 17, 252-260.

Smetana, J. G., Robinson, J., \& Rote, W. M. (2016). Socialization in adolescence. In J. E. Grusec \& P. D. Hastings (Eds.), Handbook of socialization: Theory and research (pp. 60-84). New York, NY: Guilford Press.

Spinrad, T. L., Losoya, S. H., Eisenberg, N., Fabes, R. A., Shepard, A., Cumberland, A., Guthrie, I. K., \& Murphy, B. C. (1999). The relations of parental affect and encouragement to children's moral emotions and behaviour. Journal of Moral Education, 28, 323-337.

Van der Graaff, J., Carlo, G., Crocetti, E., Koot. H. M., \& Branje, S. (2018). Prosocial behavior in adolescence: Gender differences in development and links with empathy. Journal of Youth and Adolescence, 47, 1086-1099.

Wang, M. (2019). Harsh parenting and adolescent aggression: Adolescents' effortful control as 


\section{PROSOCIAL BEHAVIORS}

the mediator and parental warmth as the moderator. Child Abuse \& Neglect, 94, 1-11.

Wentzel, K., Fillisetti, L., \& Barry, C. M. (2018). Prosocial behavior. In R. J. R. Levesque (Ed.), Encyclopedia of adolescence (2 ${ }^{\text {nd }}$ ed., pp. 2902-2910). New York, NY: Springer.

Yagmurlu, B., \& Sanson, A. (2009). Parenting and temperament as predictors of prosocial behavior in Australian and Turkish Australian children. Australian Journal of Psychology, 61, 77-88.

Yang, Y., Li, P., Fu, X., \& Kou, Y. (2017). Orientations to happiness and subjective well-being in Chinese adolescents: The roles of prosocial behavior and Internet addictive behavior. Journal of Happiness Studies, 18, 1747-1762.

Yoo, H., Feng, X., \& Day, R. D. (2013). Adolescents' empathy and prosocial behavior in the family context: A longitudinal study. Journal of Youth and Adolescence, 42, 1858-1872. 
PROSOCIAL BEHAVIORS

Table 1

Descriptive Statistics $(N=465)$

\begin{tabular}{llll}
\hline Variable & $N$ & $M(S D) / \%$ & Range \\
\hline Female gender & 478 & $51.9 \%$ & \\
Age & 465 & $15.30(1.06)$ & $13-18$ \\
African American & 489 & $12.3 \%$ & \\
All other & 489 & $21.1 \%$ & \\
Two-parent family & 460 & $67.8 \%$ & $0.00-1.00$ \\
Authoritarian parenting style & 463 & $1.58(.37)$ & $1.00-3.20$ \\
Prosocial behaviors: Friends & 465 & $4.35(.58)$ & $2.00-5.00$ \\
Prosocial behaviors: Strangers & 465 & $3.26(.73)$ & $1.11-5.00$ \\
\hline
\end{tabular}


PROSOCIAL BEHAVIORS

Table 2

Correlations

Variables

1

2

4

5

7

1. Gender

2. Age

$-.05$

3. Ethnicity: African American

$.01 \quad .04$

4. Ethnicity: All Other

.02

$.00 \quad-.19^{* *}$

5. Family structure

$-.05$

$-.04$

$-.34 * *$

$-.04$

6. Authoritarian parenting style

$-.09$

$-.0$

$.34^{* *}$

$.02 \quad-.09 *$

7. Prosocial behaviors: Friends

$.32 * *$

$-.02$

$-.19 * *$

$-.05$

$-.02-.14^{* *}$

8. Prosocial behaviors: Stranger

$.19^{* *}$

$-.03-.13 * *$

$-.03$

$.10^{*}$

$-.09$

$.57^{* *}$

Note. ${ }^{*} p<.05,{ }^{* *} p<.01,{ }^{* * *} p<.001$. 


\section{PROSOCIAL BEHAVIORS}

Table 3

Summary of Regression Analysis Predicting Prosocial Behaviors with Friends

\begin{tabular}{lcccccc}
\hline & \multicolumn{3}{c}{ Step 1 } & \multicolumn{3}{c}{ Step 2 } \\
\cline { 2 - 6 } Variable & $B$ & SE $B$ & $\beta$ & $B$ & SE $B$ & $\beta$ \\
\hline Gender & .38 & .05 & $.33^{* * *}$ & .37 & .05 & $.32^{* * *}$ \\
Age & -.00 & .02 & -.00 & -.00 & .02 & -.00 \\
Ethnicity: African American & -.45 & .08 & $-.25^{* * *}$ & -.42 & .09 & $-.23^{* * *}$ \\
Ethnicity: All Other & -.17 & .06 & $-.12^{* *}$ & -.16 & .06 & $-.11^{*}$ \\
Family structure & -.12 & .06 & $-.09 *$ & -.11 & .06 & $-.09 *$ \\
Authoritarian parenting style & & & & -.08 & .08 & -.05 \\
\hline$\Delta R^{2}$ & $.16 * * *$ & & .002 & & \\
\hline
\end{tabular}

Note. ${ }^{*} p<.05, * * p<.01, * * * p<.001$. 
PROSOCIAL BEHAVIORS

Table 4

Summary of Regression Analysis Predicting Prosocial Behaviors with Strangers

\begin{tabular}{lcccccc}
\hline & \multicolumn{3}{c}{ Step 1 } & \multicolumn{3}{c}{ Step 2 } \\
\cline { 2 - 6 } Variable & $B$ & SE $B$ & $\beta$ & $B$ & SE $B$ & $\beta$ \\
\hline Gender & .28 & .07 & $.19 * * *$ & .07 & .07 & $.19^{* * *}$ \\
Age & -.01 & .03 & -.01 & -.01 & .03 & -.02 \\
Ethnicity: African American & -.29 & .11 & $-.13^{*}$ & -.28 & .12 & $-.12^{*}$ \\
Ethnicity: All Other & -.10 & .08 & -.06 & -.10 & .08 & -.05 \\
Family structure & .09 & .08 & .06 & .10 & .08 & .06 \\
Authoritarian parenting style & & & & -.04 & .10 & -.02 \\
\hline$\Delta R^{2}$ & $.06 * * *$ & & .000 & & \\
\hline
\end{tabular}

Note. ${ }^{*} p<.05, * * p<.01, * * * p<.001$. 
Appendix A

\section{Demographic Controls}

Child's Birthdate:

Month $\overline{\text { Date }} \quad$ Year

Child's Age:

Child's Sex: $\quad$ Male $\quad$ Female

\section{Identity of Primary Caregiver}

Mother

Father

_ Both (mothers' response to this question was defining element)

Mother's Birthdate:
$\overline{\text { Month }}$

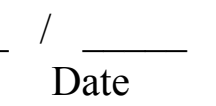

/

\section{Mother's Age:}

Mother's highest completed grade/level in school?

$1=$ Less than High School

$2=$ High School

3 = Some college

$4=$ Associates

$5=$ Bachelors

$6=$ Masters

7 = Advanced Degree (JD, Ph.D, PsyD, etc.)

Mother's current work situation:

$1=$ Working now, employed by someone else

$2=$ Self-employed

$3=$ Temporarily laid off

$4=$ Unemployed, looking for work

$5=$ Full-time homemaker

$6=$ Retired

$7=$ Permanently disabled, unable to work

$8=$ Student, not working

$9=$ Other (specify)

\section{Method of Recruitment for Family}

Polk Directory

Referral 
PROSOCIAL BEHAVIORS

Simple Family Structure

2-parent married family

Single-parent family

\section{Family's Ethnicity}

All European Americans

All African Americans

All Hispanics

All Asian Americans

All other

Multi-ethnicity 


\section{Appendix B}

\section{Parenting Styles and Dimensions Questionnaire-Short Version (PSDQ): Adult Responses}

How often do you do the following?

Response Categories:

$1=$ Never $\quad 2=$ Once in a while $\quad 3=$ About half the time $\quad 4=$ Very often $\quad 5=$ Always

$\underline{\text { Dimensions }} \quad \underline{\text { Item text }}$

Physical coercion

Verbal hostility

Non-

reasoning/punitive
- Use physical punishment as a way of disciplining my child?

- Spank when my child is disobedient?

- Grab our child when he or she is being disobedient?

- Slap our child when the child misbehaves?

- Yell or shout when my child misbehaves?

- Explode in anger towards our child?

- Scold or criticize to make our child improve?

- Scold or criticize when our child's behavior doesn't meet our expectations?

- When my child asks why they have to obey, we state: because I said so, or I am your parent, and I want you to?

- Punish by taking privileges away from my child with little if any explanations?

- Use threats as punishments with little or no explanation? (My parent uses threats as punishments with little or no explanation.)

- Punish by putting our child off somewhere alone with little if any explanations? (My parent punishes by putting me off somewhere alone with little if any explanation.) 


\section{Appendix C}

\section{Prosocial Behavior}

\section{Inventory of Strengths Scale}

Instructions: Using the response categories, please read the items carefully and rank how you engage in prosocial behaviors with friends and strangers.

Response Categories:

$1=$ Never $\quad 2=$ Once in a while $\quad 3=$ About half the time $\quad 4=$ Very often $5=$ Always

Child's prosocial behavior towards friends and others/strangers

Response

\section{Others/Strangers}

I help people I don't know, even if it is not easy for me.

I really enjoy doing small favors for people I do not know.

I go out of my way to cheer up people who seem sad, even if I do not know

them.

I voluntarily help my neighbors.

I help other kids at school (with things like homework, sports, or other activities).

I volunteer in programs to help others in need (like food or clothing drives, service groups or other volunteer projects).

I am involved in service at my school (such as student council or student government).

I enjoy being kind to others, even if I do not know them

I watch out for kids at school, even if I do not know them.

\section{Friends}

I help my friends, even if it is not easy for me.

I really enjoy doing small favors for my friends.

I go out of my way to cheer up my friends when they seem sad.

I voluntarily help my friends.

I always listen to my friends talk about their problems.

I enjoy being kind to my friends.

I love to make my friends happy.

I tell my friends how much they mean to me.

I watch out for my friends. 
PROSOCIAL BEHAVIORS

\section{Appendix D}

Table D1

Descriptive Statistics for Authoritarian Parenting Elements

\begin{tabular}{lccl}
\hline Variable & $N$ & $M(S D) / \%$ & Range \\
\hline Physical coercion & 463 & $1.13(.29)$ & $1.00-2.75$ \\
Verbal hostility & 463 & $2.05(.62)$ & $1.00-4.25$ \\
Nonreasoning/punitive & 463 & $1.54(.50)$ & $1.00-3.75$ \\
\hline
\end{tabular}




\section{PROSOCIAL BEHAVIORS}

\section{Table D2}

\section{Correlations}

Variables 1

2 3 4

1. Physical coercion

2. Verbal hostility $.36 * * *$

3. Nonreasoning/punitive

$.42 * * *$ $.41 * *$

4. Prosocial behaviors: Friends

$-.12 * *$

$-.08$

$.14 * *$

5. Prosocial behaviors: Strangers

$-.07$

$-.02$

$-.14 * *$

$.58 * * *$

Note. ${ }^{*} p<.05, * * p<.01, * * * p<.001$. 
PROSOCIAL BEHAVIORS

Table D3

Summary of Regression Analysis Predicting Prosocial Behaviors with Friends

\begin{tabular}{lrrrrrr}
\hline & \multicolumn{3}{c}{ Step 1 } & \multicolumn{3}{c}{ Step 2 } \\
\cline { 2 - 7 } Variable & \multicolumn{1}{c}{ SE $B$} & $\beta$ & $B$ & SE $B$ & \multicolumn{1}{c}{$B$} \\
\hline Gender & .38 & .05 & $.33^{* * *}$ & .37 & .05 & $.32^{* * *}$ \\
Age & -.00 & .02 & -.00 & -.00 & .02 & -.01 \\
Ethnicity: African American & -.45 & .08 & $-.25^{* * *}$ & -.42 & .10 & $-.24^{* * *}$ \\
Ethnicity: All Other & -.17 & .06 & $-.12^{* *}$ & -.16 & .06 & $-.12^{* *}$ \\
Family structure & -.12 & .06 & $-.09^{*}$ & -.12 & .06 & $-.09^{*}$ \\
Physical coercion & & & & .02 & .11 & .01 \\
Verbal hostility & & & & -.02 & .05 & -.02 \\
Nonreasoning/punitive & & & & -.05 & .06 & -.05 \\
\hline$\Delta R^{2}$ & $.16^{* * *}$ & & & .003 & & \\
\hline
\end{tabular}

Note. ${ }^{*} p<.05,{ }^{* *} p<.01,{ }^{* * *} p<.001$. 
PROSOCIAL BEHAVIORS

Table D4

Summary of Regression Analysis Predicting Prosocial Behaviors with Strangers

\begin{tabular}{lrrrrrr}
\hline & \multicolumn{3}{c}{ Step 1 } & \multicolumn{3}{c}{ Step 2 } \\
\cline { 2 - 7 } Variable & $B$ & SE $B$ & $\beta$ & $B$ & SE $B$ & $\beta$ \\
\hline Gender & .28 & .07 & $.19 * * *$ & .27 & .07 & $.19^{* * *}$ \\
Age & -.01 & .03 & -.01 & -.01 & .03 & -.02 \\
Ethnicity: African American & -.29 & .11 & $-.13 * *$ & -.25 & .13 & $-.11^{* *}$ \\
Ethnicity: All Other & -.10 & .08 & -.06 & -.10 & .08 & -.06 \\
Family structure & .09 & .08 & .06 & .08 & .08 & .05 \\
Physical coercion & & & & .09 & .15 & .04 \\
Verbal hostility & & & & .05 & .06 & .04 \\
Nonreasoning/punitive & & & & .008 & .08 & -.10 \\
\hline$\Delta R^{2}$ & $.06^{* * *}$ & & & & & \\
\hline
\end{tabular}

Note. ${ }^{*} p<.05, * * p<.01, * * * p<.001$. 